Letters to the Editor

\title{
Separation of Catecholamines by Capillary Zone Electrophoresis Using Complexation with Boric Acid
}

\author{
Shunitz Tanaka, Takashi Kaneta and Hitoshi Yoshida \\ Department of Chemistry, Faculty of Science, Hokkaido University, Sapporo 060, Japan
}

Keywords Capillary zone electrophoresis, catecholamine, boric acid, borate complex

Capillary zone electrophoresis (CZE) is a new separation technique performed in a narrow glass tube by applying a high voltage. In the capillary an electroosmotic flow greater than the electrophoretic velocity of solutes is generated; all species (cationic, anionic and neutral) can then be migrated in the same direction and detected. CZE was introduced by Mikker $e t$ al. ${ }^{1}$ and its high resolution was demonstrated by Jorgenson et al. . $^{2-4}$ The utility of CZE for the separation of many ionized compounds has also been refined by many workers..$^{5-9}$ Moreover, micellar electrokinetic capillary chromatography (MECC), in which the partition between the micellar and an aqueous phase is used to improve the separability of CZE, made it possible to separate many neutral compounds. ${ }^{10,11}$

CZE has been applied mainly to the separation of biological samples, e.g. amino acids ${ }^{5}$, peptides 8 , nucleotides $^{7,9}$ and so on. Catecholamines, which play an important role as a neurotransmitter, could also be separated by CZE. Wallingford et al. reported the separation of catecholamines by MECC and their sensitive electrochemical detection by a carbon fiber electrode. ${ }^{12-14}$ However, this method has a difficulty in that the surfactant added for the formation of micelle reduces the sensitivity of the electrochemical detection for catecholamines. The separation of catecholamines has not yet been investigated in detail.

We have reported that the use of complexation between catechol and boric acid is efficient for the separation of catechols by capillary tube isotachophoresis. ${ }^{15,16}$ In the present work we describe the separation of catecholamines by CZE using complexation with boric acid. Without complexation, their effective mobilities are close to each other and separation is difficult. By adding boric acid to the operating buffer, the resolution of catecholamines can be improved and the separation of eight catecholamines achieved.

\section{Experimental}

\section{Apparatus}

A fused silica capillary tube (70-cm length with a $100-$ $\mu \mathrm{m}$ i.d.) was obtained from Gasukuro Kogyo (Tokyo, Japan). A high-voltage power supply of Shimadzu IP1B isotachophoretic analyzer (Kyoto, Japan) was used for applying a high voltage. A ISCO $\mathrm{CV}^{4}$ variablewavelength absorbance detector (ISCO, Inc. Nebraska, USA) was used as a detector. Detection was carried out by measuring the absorbance at $217 \mathrm{~nm}$ on the column at a position $20 \mathrm{~cm}$ from the negative end of the capillary tube. A sample was injected by moving the injection end of capillary to the sample reservoir and raising it higher than the other end. The electroosmotic flow rate was measured in terms of the methanol peak.

\section{Reagents}

All reagents were of analytical grade and used without further purification. Epinephrine (EP), isoproterenol (IP), 3,4-dihydroxyphenylalanine (Dopa) and vanillylmandelic acid (VMA) were obtained from Wako Pure Chemicals (Osaka, Japan). Methanephrine (MN) and normethanephrine (NM) were obtained from Nacalai Tesque Inc. (Kyoto, Japan). Norepinephrine (NE) and dopamine (DA) were from Aldrich Chemical Co. (Wisconsin, USA) and Sigma Chemical Co. (Missouri, USA), respectively. The solutions were stored in a refrigerator.

\section{Results and Discussion}

The dissociation constants $\left(\mathrm{p} K_{\mathrm{a}}\right)$ of amino groups in catecholamines are around 9 . These substances can be migrated as cations, except for Dopa and VMA in an ammonia buffer solution. However, those effective mobilities are close to each other, and separation is difficult. This fact can not be improved by merely controlling the pH. On the other hand, Dopa and VMA have a carboxyl group and exist as anions in an ammonia buffer. Therefore, Dopa and VMA migrate in the direction opposite to the electroosmotic flow and their peaks are sufficiently separated from those of other catecholamines. By adding boric acid to the operating buffer, the retention time of each solute can be increased, as shown in Fig. 1. The compounds with 


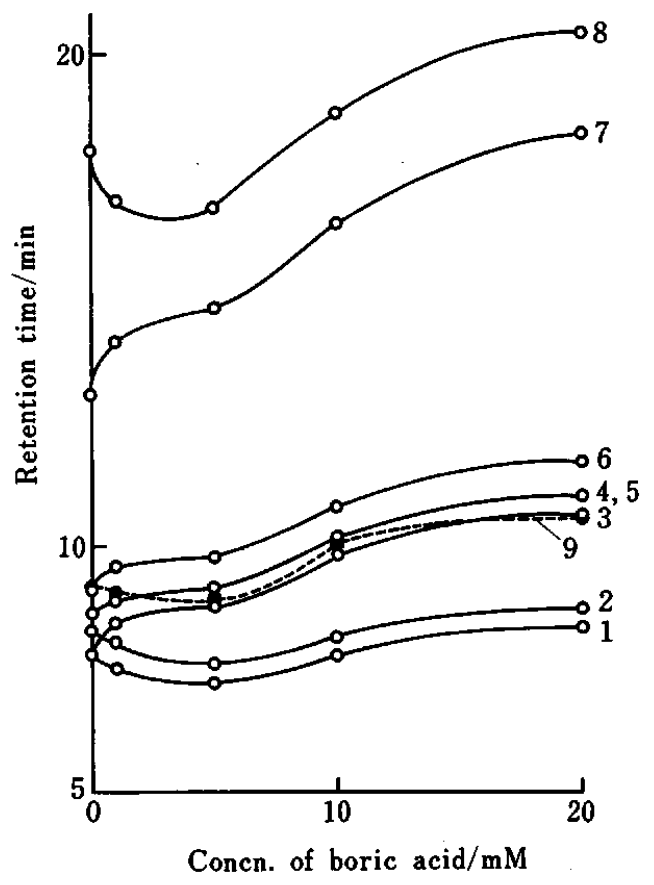

Fig. 1 Effect of the concentration of boric acid in the operating buffer. Buffer, $50 \mathrm{mM} \mathrm{HCl}+100 \mathrm{mM} \mathrm{NH}_{3}$; current, $100 \mu \mathrm{A}$ (the voltage is about $11.5 \mathrm{kV}$ ); $1, \mathrm{MN} ; 2, \mathrm{NM} ; 3, \mathrm{DA}$; 4, IP; 5, EP; 6, NE; 7, Dopa; 8, VMA; 9, electroosmotic flow (methanol); detection wavelength, $217 \mathrm{~nm}$.

a catechol structure are considered to react with boric acid while forming borate complexes of neutral or negative charge. The resolution is improved by increasing the concentration of boric acid. Especially, the separation of MN from DA, which has been very difficult with an operating system without borate ions, was achieved completely. DA has two hydroxyl groups constituting a catechol structure, whereas $\mathrm{MN}$ has one hydroxyl and one methoxyl group. DA is thus affected by borate ions more than $\mathrm{MN}$ and the resolution is increased. However, if boric acid was less than $20 \mathrm{mM}$, EP and IP could not be separated, even in the presence of borate ions. To increase the effect of complexation with borate ions, an operating system comprising a borate buffer has been further investigated.

Figure 2 illustrates the electropherogram obtained using a borate buffer of $100 \mathrm{mM} \mathrm{KOH}-200 \mathrm{mM}$ boric acid solution. Under this condition, not only the resolution of EP and IP was improved but also eight catecholamines could be separated. By increasing the concentration of borate, the catecholamines can be efficiently complexed with borate, producing anions of higher charged states. It is reasonable to conclude that the resolution is improved because the migrating direction of sample ions is reversed to the direction of electroosmotic flow.

It has been confirmed that the use of a borate buffer is capable of separating catecholamines by CZE. An investigation concerning the control of the electroosmotic flow by cationic surfactants is in progress in order to further improve the resolution.

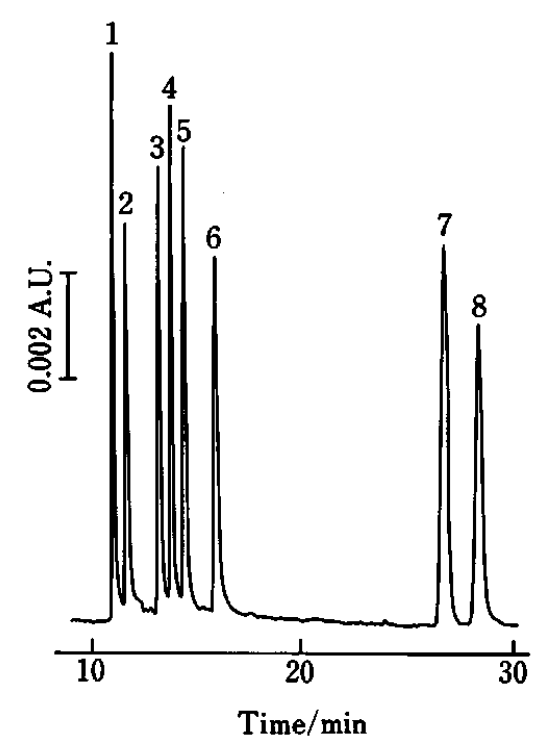

Fig. 2 Electropherogram of catecholamines. Buffer, $100 \mathrm{mM}$ $\mathrm{KOH}+200 \mathrm{mM}$ boric acid; current, $100 \mu \mathrm{A}$ (the voltage is about $9.5 \mathrm{kV}$ ); sample, mixture of $1 \mathrm{mM}$ of each catecholamine; injection time, $10 \mathrm{~s}$; other conditions are the same as in Fig. 1.

\section{References}

1. F. E. P. Mikkers, F. M. Everaerts and Th. P. E. M. Verheggen, J. Chromatogr., 169, 11 (1979).

2. J. W. Jorgenson and K. D. Lukacs, J. Chromatogr., 218, 209 (1981).

3. J. W. Jorgenson and K. D. Lukacs, Anal. Chem., 53, 1298 (1981).

4. J. W. Jorgenson and K. D. Lukacs, Science [Washington, D. C.], 222, 266 (1983).

5. P. G. E. Gassman, H. Michelsen and R. N. Zare, Anal. Chem., 59, 44 (1987).

6. S. Fujiwara and S. Honda, Anal. Chem., 59, 487 (1987).

7. A. S. Cohen, S. Terabe, J. A. Smith and B. L. Karger, Anal. Chem., 59, 1021 (1987).

8. R. M. McCormick, Anal. Chem., 60, 2642 (1988).

9. W. G. Kuhr and E. S. Yeung, Anal. Chem., 60, 2642 (1988).

10. S. Terabe, K. Otsuka, K. Ichikawa, A. Tsuchiya and T. Ando, Anal. Chem., 56, 111 (1984).

11. S. Terabe, K. Otsuka and T. Ando, Anal. Chem., 57, 834 (1985).

12. R. A. Wallingford and A. G. Ewing, Anal. Chem., 59, 1762 (1987).

13. R. A. Wallingford and A. G. Ewing, Anal. Chem., 60, 258(1988).

14. A. G. Ewing, R. A. Wallingford and T. M. Olefirowicz, Anal. Chem., 61, 292A (1989).

15. S. Tanaka, T. Kaneta and H. Yoshida, Anal. Sci., 5, 217 (1989).

16. S. Tanaka, T. Kaneta and H. Yoshida, J. Chromatogr., 498, 205 (1990).

(Received December 27, 1989)

(Accepted March 5, 1990) 